\title{
Biases and Improvements of the ENSO- East Asian Winter Monsoon Teleconnection in CMIP5 and CMIP6 Models
}

Wenping Jiang ( $\nabla_{\text {jiangwenping@hhu.edu.cn ) }}$

Hohai University, China https://orcid.org/0000-0001-5065-8028

Hainan Gong

Chinese Academy of Sciences

Ping Huang

Chinese Academy of Sciences

Lin Wang

Chinese Academy of Sciences

Gang Huang

Chinese Academy of Sciences

Lisuo $\mathrm{Hu}$

Chinese Academy of Sciences

\section{Research Article}

Keywords: ENSO-EAWM teleconnection bias, cold tongue bias, anomalous Northwest Pacific anticyclone, CMIP5, CMIP6

Posted Date: August 17th, 2021

DOl: https://doi.org/10.21203/rs.3.rs-673765/v1

License: (c) (i) This work is licensed under a Creative Commons Attribution 4.0 International License.

Read Full License

Version of Record: A version of this preprint was published at Climate Dynamics on March 6th, 2022. See the published version at https://doi.org/10.1007/s00382-022-06220-5. 


\section{Abstract}

The influence of El Niño-Southern Oscillation (ENSO) on the East Asian winter monsoon (EAWM) is investigated based on the outputs of phase 6 of the Coupled Model Intercomparison Project (CMIP6) models and compared to that in phase 5 (CMIP5). Results show that the CMIP6 models generally reproduce the ENSO-EAWM teleconnection more realistically than the CMIP5 models, although they still somewhat underestimate the ENSO-EAWM teleconnection than observed. Based on the inter-model spread of ENSO-EAWM teleconnection simulated in the CMIP5/CMIP6 models, we reveal that the commonly underestimated ENSO-EAWM teleconnection among the models can be traced back to the excessive cold tongue bias in the equatorial western Pacific. A model with a stronger climatological cold tongue favors generating a more westward extension of the ENSO-related SST anomaly pattern, which in turn forces an anomalous cyclonic circulation over the Northwest Pacific (NWP). It offsets the anticyclonic anomalies in the NWP triggered by the warm ENSO-related SST anomalies in the tropical Indian Ocean and the central-eastern Pacific and weakens the ENSO-EAWM teleconnection. Compared with the CMIP5 models, CMIP6 models better simulate SST mean state and the resultant ENSO-EAWM teleconnection. The present results suggest that substantial efforts should be made to reduce the bias in the mean-state SST for further improving the simulation and projection of the East Asian-western Pacific winter climate.

\section{Introduction}

The East Asian winter monsoon (EAWM), one of the most active monsoon systems during boreal winter, exerts a large influence on the weather and climate in East Asia (Chen et al. 2000; Chen et al. 2005; Chang et al. 2006; Wang and Lu 2017). The anomalies of the EAWM could lead to the potential occurrence of cold extremes in East Asia and severe flooding in surrounding Southeast Asian countries and cause profound societal and economic impacts (Ding 1994; Chang et al. 2006; Wang et al. 2009a; Wang et al. 2009b; Feng et al. 2010; Huang et al. 2012; Ma et al. 2018; Ma et al. 2020).

The EAWM exhibits a strong interannual variability, which is not only controlled by the mid- and high latitudes factors such as the Arctic Oscillation (Gong et al. 2001; Wu and Wang 2002; Gong et al. 2017), Arctic sea ice (Wu et al. 2011; Chen et al. 2014; Wang and Chen 2014; Sun et al. 2016; Gong et al. 2021), and blockings over Eurasia (Wang et al. 2010; Cheung et al. 2012; Cheung and Zhou 2015), but also significantly influenced by tropical sea surface temperature (SST) anomalies such as El Niño-Southern Oscillation (ENSO) (Zhang et al. 1996; Chen et al. 2000; Wang et al. 2000; Wang et al. 2008b). ENSO has a profound influence on global climate through exciting atmospheric circulation anomalies (Horel and Wallace 1981; Wang et al. 2000; Hu et al. 2021; Yang and Huang 2021). An anomalous anticyclone (cyclone) generates over the Northwest Pacific (NWP) during El Niño (La Niña) mature winter, and its associated meridional anomalies weaken (enhance) the EAWM flow and lead to warmer (cooler) and wetter (dryer) climate in East Asia and Southeast Asian countries (Zhang et al. 1996; Wang et al. 2000; Wang et al. 2013). Therefore, the anomalous anticyclone (cyclone) is a key bridge linking ENSO to the East Asia-western Pacific winter climate (Zhang et al. 1996). 
Climate models are effective tools for understanding and projecting EAWM variability. The performance of models in reproducing ENSO-EAWM teleconnection behaviors is important for determining the reliability of the model's projections of future East Asia-western Pacific winter climate change. Previous studies suggested, using the climate models participating in phase 3 of the Coupled Model Intercomparison Project (CMIP3) and phase 5 (CMIP5), that the representation of the ENSO-EAWM relationship in CMIP3 and CMIP5 models depends on the amplitude and the longitudinal extension of ENSO-related sea surface temperature (SST) pattern (Gong et al. 2014; Gong et al. 2015). Moreover, the performance of CMIP5 models in representing ENSO's influences on the East Asian-western Pacific winter climate is better than that of CMIP3 models (Gong et al. 2015). Recently, the outputs from the latest climate system models for CMIP6 have been released. CMIP6 models have been improved in comparison to CMIP5 models in terms of the dynamic core and the model physics (Jiang et al. 2020a; Xia et al. 2020; $X$ in et al. 2020). Therefore, this study addresses the following questions: How well do the latest CMIP6 models simulate the ENSO-EAWM teleconnection? Compared with CMIP5 models, do CMIP6 models have higher skill in simulating the ENSO-EAWM teleconnection? If so, what processes are responsible for the improvements?

Based on the outputs from 20 CMIP5 and 20 CMIP6 models, the present study investigates the biases of CMIP6 models in reproducing the observed ENSO-EAWM teleconnection and compares the results to those in CMIP5 models. We show that the simulation of the ENSO-EAWM teleconnection is significantly improved in CMIP6 and reveal a solid linkage of the simulations between the ENSO-EAWM teleconnection and the climatological cold tongue strength in the equatorial Pacific. Our results highlight the importance of simulating a realistic cold tongue strength in reproducing ENSO-EAWM teleconnection.

The rest of the paper is organized as follows. Section 2 describes the reanalysis datasets, models and methods used in this study. Section 3 shows the biases in simulating the ENSO-EAWM teleconnection in models. Section 4 investigates the origins of simulated ENSO-EAWM teleconnection biases based on 40 CMIP5/6 models. Section 5 compares the performances of the two generations models. Section 6 provides a summary and discussion.

\section{Data And Methods}

\subsection{Models and observations}

The monthly mean outputs of the historical run from 20 CMIP5 models (Taylor et al. 2012) and 20 CMIP6 models (Eyring et al. 2016) are used in this study. The names of these models are listed in Table 1. We only analyzed the first realization ('r1i1p1' for CMIP5 and 'r1i1p1f1' for CMIP6) of each model. The monthly mean SST, atmospheric variables and precipitation from 1961 to 2000 are used. For comparing with observations, we also use the observational monthly mean SST data from the Extended Reconstructed SST, version 3 (ERSST. v3) (Smith et al. 2008), which has a horizontal resolution of $2^{\circ} \times 2^{\circ}$ (available at https://www.esrl.noaa.gov/psd/data/gridded/data.noaa.ersst.html). The monthly mean wind and precipitation are from the National Centers for Environment Prediction-National Center for 
Atmospheric Research (NCEP/NCAR) reanalysis dataset with a horizontal resolution of $2.5^{\circ} \times 2.5^{\circ}$, covering the period from 1961 to 2010 (Kalnay et al. 1996) (available at https://www.esrl.noaa.gov/psd/data/gridded/data.ncep.reanalysis.html). All the model outputs and observational datasets are horizontally interpolated onto the same $2.5^{\circ} \times 2.5^{\circ}$ grid before analysis.

\subsection{Methods}

The boreal winter Niño-3.4 index [defined as the December-February (DJF) SST anomalies averaged over the region $\left.\left(5^{\circ} \mathrm{S}-5^{\circ} \mathrm{N}, 120^{\circ}-170^{\circ} \mathrm{W}\right)\right]$ represents the ENSO variability. The unstandardized Niño-3.4 index is regressed onto the interannual anomalies of SST, circulation, and precipitation to display the ENSOrelated variability. In this study regressed anomalies are calculated in each model first and then are averaged across the models with equal weights, which is denoted as the MME. The inter-model consensus is considered as high if more than $70 \%$ of models agree on the sign of the MME (Jiang et al. 2018; He et al. 2019), since the threshold of $70 \%$ intermodal consensus is approximately equal to $95 \%$ statistical significance calculated by the Student's $t$ test (Power et al. 2012). To quantify the EAWM variability, we use the EAWM index [defined as the area-averaged 1000-hPa meridional winds for the coast of eastern Asia $\left(10^{\circ}-30^{\circ} \mathrm{N}, 115^{\circ}-130^{\circ} \mathrm{E}\right)$ ] following $\mathrm{Ji}$ et al. (1997). Our focus is on boreal winter (DJF), which is the typical peak season for ENSO. Unless stated otherwise in the text, all results are for the winter season only.

Inter-model multivariate empirical orthogonal function (MV-EOF) analysis is an extended method based on the conventional EOF (Wang 1992; Wang et al. 2008a; Zhou et al. 2019; Zhou et al. 2020), which is performed to extract the leading mode of the inter-model diversity in simulating ENSO-EAWM relationship. The MV-EOF analysis can capture dominant patterns in the spatial phase relationships among several related variables, which favors physical insight into the interactive processes within a complex climate system (Wang 1992; Wang et al. 2008a; Zhou et al. 2019; Zhou et al. 2020). In this study, the MME value of each variable is first removed before the inter-model MV-EOF, and then each variable is standardized to coherent magnitude. The inter-model MV-EOF analysis is based on three variables related to the EAWM, including zonal and meridional winds at $850-\mathrm{hPa}$ and precipitation in the region $\left(0^{\circ}-40^{\circ} \mathrm{N}, 100^{\circ}-150^{\circ} \mathrm{E}\right)$. The first mode in the inter-model MV-EOF analysis is selected, and the other variables related to the EAWM are regressed onto the normalized first principal component (PC1).

\section{The Enso-eawm Teleconnection Biases In Cmip5 And Cmip6 Models}

ENSO is a crucial factor to impact the interannual variability of the EAWM (Huang et al. 2012). The primary climate effect of ENSO is represented in terms of precipitation and atmospheric circulation anomalies (Bellenger et al. 2014). To evaluate the model performance in simulating the ENSO-EAWM relationship in CMIP5 and CMIP6 model, Figs. 1a-c show the precipitation anomalies and 850-hPa wind anomalies associated with ENSO in observations, the CMIP5 MME and the CMIP6 MME. Although the two generations of models can roughly reproduce the ENSO-related anomalous low-level anticyclone 
located over the NWP which bridges the teleconnection between ENSO and EAWM (Figs. 1a-c), there still exist some biases, such as a weak rain belt stretching from southern China to the south of Japan, weak anticyclonic circulation anomalies and resultant rainfall anomalies over the NWP and stronger rainfall anomalies over the equatorial western Pacific (EWP) in CMIP5 MME and CMIP6 MME relative to those in observations (Figs. 1d-e).

Since the ENSO affects the EAWM mainly through the southerly anomalies of the west side of anomalous anticyclone (e.g., Chen et al. 2000; Wang and Chen 2010b; Gong et al. 2015), the low-level ENSO-related meridional wind anomaly bias in the region of the EAWM index defined in Ji et al. (1997) is employed to quantitatively illustrate the influence of ENSO on the EAWM in models. Here, the area-averaged 1000-hPa ENSO-related meridional wind anomaly bias in the region $\left(10^{\circ}-30^{\circ} \mathrm{N}, 115^{\circ}-130^{\circ} \mathrm{E}\right)$ in individual models are shown in Fig. 2. Although the simulated ENSO-related meridional wind anomaly bias varies from model to model, most models simulated an overly weak meridional wind anomaly (with a negative bias) (Fig. 2a-b). In contrast, a small number of models can roughly reproduce the observed meridional wind anomaly associated with ENSO, such as ACCESS1-3 and GFDL-ESM2G in CMIP5 (Fig. 2a), CAMS-CSM10, CESM2, CNRM-CM6-1, FGOALS-f3-L, FGOALS-g3, and GFDL-ESM4 in CMIP6 (Fig. 2b).

\section{Origins Of The Models Bias In Enso-eawm Teleconnection}

Based on the inter-model diversity, we investigate the origins of ENSO-related EAWM variability biases in CMIP5 and CMIP6 models. The inter-model MV-EOF analysis of the combined three atmospheric variables is performed to extract the leading spread of the simulated ENSO-EAWM teleconnection in the East Asia-NWP region $\left(0^{\circ}-40^{\circ} \mathrm{N}, 100^{\circ}-150^{\circ} \mathrm{E}\right)$. Figure 3 shows the first inter-model MV-EOF mode of the ENSO-related low-level atmospheric circulation and precipitation anomalies and the corresponding normalized PC1. The first mode explains $27 \%$ of the total variance of the inter-model spread in simulating ENSO-EAWM teleconnection. The first inter-model MV-EOF exhibits positive rainfall anomalies over the NWP and negative rainfall anomalies over southern China and over the equatorial central Pacific. In association with the precipitation anomaly pattern, there generates a cyclonic circulation anomaly over the NWP and an anticyclonic circulation anomaly over southern China (Fig. 3a). The first inter-model MVEOF pattern is very similar to the biases simulated in the CMIP5 MME and the CMIP6 MME (Figs. 1d-e), which suggests that the biases in CMIP5 MME and CMIP6 MME dominate the inter-model spread in the simulated ENSO-related EAWM variability.

Previous studies suggested that the simulation of subtropical circulation and precipitation anomalies over the East Asia-NWP region are closely related to the simulation of tropical SST anomaly (Jiang et al. 2017; Tao et al. 2018; Li et al. 2019). The regressed tropical SST anomalies onto the normalized PC1 exhibit a significant and positive center in the EWP, which is a well-known ENSO-related SST bias-the excessive westward extension of ENSO-related SST variability (Fig. 4a) (Collins et al. 2010; Kim and Yu 2012; Kug et al. 2012; Chowdary et al. 2014; Jiang et al. 2021). In response to the warm SST anomalies in the EWP, the tropospheric temperature is warmed over the western Pacific with upper-level anticyclonic anomalies over the NWP (Fig. 4b), and a pair of low-level cyclonic patterns straddle the equator over the 
NWP and Australia as a Gill-type Rossby wave response (Matsuno 1966; Gill 1980) (Fig. 4c). The lowlevel cyclonic circulation over the NWP reduces the original anticyclonic circulation anomalies over the NWP, leading to an underestimated ENSO-EAWM relationship in most models.

The inter-model MV-EOF results suggest that the underestimated ENSO-EAWM teleconnection in CMIP5/6 models may be attributed to the excessive westward extension of ENSO-related SST variability.

Furthermore, Jiang et al. (2021) pointed out the excessive westward extension of ENSO-related SST bias can trace back to the overly strong cold tongue (CT) in the EWP. A model with a stronger CT favors a larger zonal SST gradient in the EWP and then generates stronger zonal advection feedback, which ultimately contributes to a larger ENSO-related SST variability in the EWP. Thus, we hypothesize that the performance of CMIP5 and CMIP6 models in simulating ENSO-EAWM teleconnection may be rooted in the simulated SST mean state.

To elucidate the effect of the excessive CT on the simulation of the ENSO-EAWM teleconnection, we calculate the inter-model regression of the ENSO-related precipitation and atmospheric circulation anomalies onto a CT index [defined as the mean-state SST averaged over the CT region $\left(2^{\circ} \mathrm{S}-2^{\circ} \mathrm{N}\right.$, $150^{\circ} \mathrm{E}-150^{\circ} \mathrm{W}$ ) in the historical run multiplied by -1$]$. The multiplication by -1 is used to produce a larger CT index value to denote a stronger CT (Ying et al. 2019; Jiang et al. 2020b; Jiang et al. 2021). The regressed ENSO-related precipitation and low-level circulation anomaly patterns onto CT index (Fig. 5a) closely resemble the leading inter-model mode in simulating the ENSO-related precipitation and low-level circulation anomaly patterns shown in Fig. 3a. It means that a model with a stronger CT tends to simulate a weaker ENSO-EAWM relationship, namely a weaker rain belt over southern China and the south of Japan, stronger cyclonic circulation anomalies, and resultant more rainfall anomalies over the NWP (Fig. 5a). The regressed ENSO-related SST pattern onto CT index (Fig. 5b) is very similar to the leading inter-model mode in the simulated ENSO-related SST pattern (Fig. 4a). Jiang et al. (2021) revealed the CT strength is the leading source of the inter-model spread of simulated ENSO-related SST variability in the EWP. Moreover, the standardized PC1 is highly correlated with the CT strength, with a high inter-model correlation of 0.64, exceeding the 99\% confidence level based on the Student's $t$ test (Fig. 5c). These results indicate that the simulated CT strength is the leading source of the inter-model spread of ENSO-EAWM teleconnection.

Figure 6 reorganizes the linkage from the simulated CT strength, the ENSO-related SST anomalies in the EWP and the ENSO-EAWM relationship in the individual CMIP5 and CMIP6 models. The CT strength is closely related to the simulated ENSO-related SST anomalies in the EWP with an inter-model correlation coefficient of 0.77 (Fig. 6a), which is because that a stronger CT leads to a larger zonal SST gradient in the EWP, then generates stronger zonal advection feedback in the EWP and finally a larger SST variability in the EWP (Jiang et al. 2021). The warmer EWP SST anomalies could force a stronger cyclonic circulation over the NWP through triggering a Gill-type atmospheric response, then make a weaker relationship between ENSO and EAWM (Fig. 6b; correlation coefficient -0.54). Finally, a model with a strong CT tends to simulate a weaker ENSO-EAWM relationship (Fig. 6c; correlation coefficient - 0.37 ). The above processes exceed the $95 \%$ confidence level based on the Student's $t$ test. 


\section{Improvements In Simulating The Enso-eawm Teleconnection In Cmip6 Models}

The MME result shows that the biases of the ENSO-EAWM teleconnection in CMIP6 are relatively smaller than those in CMIP5 (Figs. 1d-f). Moreover, although both the CMIP5 MME and CMIP6 MME underestimate the ENSO-EAWM relationship, the magnitude of ENSO-related meridional wind bias in CMIP6 MME is almost one-third of that in CMIP5 MME (Fig. 2). Figure 6 also exhibits the improvement of CMIP6 MME in each physical node from the CT strength to the relationship between ENSO and EAWM relative to the CMIP5 MME. Thus, there is an overall improvement in the simulated ENSO-EAWM relationship in CMIP6 models.

Inspired by these results based on the inter-model diversity, we suppose that the improvement in simulating ENSO-EAWM teleconnection in CMIP6 models may be associated with the improved ENSOrelated SST variability in the EWP, and ultimately with the improved CT strength. Therefore, Fig. 7 provides the ENSO-related SST anomaly patterns in observations, the CMIP5 MME, the CMIP6 MME and their differences, respectively. Although the positive ENSO-related SST anomaly bias in the EWP still exists in the CMIP6 MME (Figs. 7c and 7e), the simulated ENSO-related SST pattern in CMIP6 MME are closer to observations than that in CMIP5 MME (Figs. 7a - c), and the magnitude of this bias in the CMIP6 MME has been significantly reduced relative to the CMIP5 MME (Figs. $7 d-f$ ).

Similarly, the improvement of the simulated CT pattern can be clearly seen in the CMIP6 MME relative to the CMIP5 MME from Fig. 8. A common cold SST bias generates in the equatorial western-central Pacific, i.e. the excessive CT bias, with a center at around $180^{\circ}$ both in the CMIP5 and CMIP6 MME (Figs. $8 \mathrm{~d}$ and 8 e). However, the magnitude of the cold SST bias in the equatorial western-central Pacific is significantly improved in the CMIP6 MME (Fig. 8f), which confirms the role of the simulated overly strong CT bias in the underestimated ENSO-related EAWM variability biases in CGCMs. Namely, the improvement of CMIP6 MME in simulating ENSO-EAWM teleconnection can trace back to the improvement of simulated CT strength. All these results highlight the importance of simulated CT strength for the ENSO-EAWM teleconnection.

\section{Summary And Discussions}

In this study, the ENSO-EAWM teleconnection is evaluated based on 20 CMIP5 models and 20 CMIP6 models. Overall, these state-of-the-art models underestimate the ENSO-EAWM teleconnection with weak anticyclone anomalies over the NWP and rainfall anomalies over southern China and the south of Japan, potentially limiting the model's skill in predicting the winter climate in the East Asia-western Pacific. However, comparing with the CMIP5 models, the simulation skill of the ENSO-EAWM teleconnection has been commonly improved in the CMIP6 MME, with more realistic anticyclone anomalies over the NWP and rainfall anomalies in southern China and the south of Japan. Based on the inter-model diversity of simulated ENSO-related EAWM variability, we identify a solid linkage between the ENSO-EAWM teleconnection and the CT strength in the EWP in CMIP5 and CMIP6 models. Specifically, a model with an 
overly strong CT tends to simulate an excessive westward extension of ENSO-related SST anomalies in the EWP through modulating zonal advection feedback (Jiang et al. 2021). Meanwhile, a model with a stronger ENSO-related SST variability in the EWP tends to underestimate the ENSO-EAWM relationship. The warm SST anomalies in the EWP can directly force a Rossby wave response in the NWP, weakening the anomalous anticyclonic circulation and associated rainfall anomalies there triggered by the tropical central-eastern SST anomalies. Therefore, as expected, the improvement of ENSO-EAWM teleconnection in the CMIP6 MME can be traced back to the improvement of climatological CT strength.

The excessive CT bias in the equatorial Pacific has persisted in several generations of climate models ( $\mathrm{Li}$ and Xie 2014; Li et al. 2015). Previous studies found that the overly strong CT bias can significantly influence the simulation of the ENSO-NWP summer monsoon teleconnection (Jiang et al. 2017; Li et al. 2019) and the projection of ENSO behaviors (Jiang et al. 2020b). The present study suggests that the simulation of CT strength also interferes with the ENSO-EAWM teleconnection during the mature phase of ENSO. All these studies highlight the importance of the simulated SST mean state in models. However, the origins of the overly strong CT are still controversial, including too strong trade winds (Guilyardi et al. 2009), biases in the convection scheme (Song and Zhang 2009), an underestimated negative shortwaveSST feedback (Bayr et al. 2018; Bayr et al. 2019), a positive evaporation-SST feedback (Zhang and Song 2010), and an overly weak surface heating due to biases in the cloud cover (Sun et al. 2003). More studies about the origins of the CT bias should be further investigated in the future.

\section{Declarations}

\section{Acknowledgments}

This work was supported by the Natural science foundation of Jiangsu Province (BK20200532), the National Natural Science Foundation of China (42005022, 41975116, 91937302, 41721004 and 42075033), the Fundamental Research Funds for the Central Universities (B210202139), and the Postdoctoral Science Foundation of Zhejiang Province (ZJ2020164). The observed SST data used during this study are openly available from the Extended Reconstructed SST, version 3 (ERSST. v3) dataset at https://www.esrl.noaa.gov/psd/data/gridded/data.noaa.ersst.html as cited in Smith et al. (2008). And the monthly mean wind and precipitation are from the National Centers for Environment PredictionNational Center for Atmospheric Research (NCEP/NCAR) reanalysis dataset with a horizontal resolution of $2.5^{\circ} \times 2.5^{\circ}$, covering the period from 1961 to 2010 (Kalnay et al. 1996) (available at https://www.esrl.noaa.gov/psd/data/gridded/data.ncep.reanalysis.html). The CMIP5 model datasets are available at https://esgf-node.IInl.gov/search/cmip5/. And the CMIP6 model datasets are publicly available at https://esgf-node.IInl.gov/search/cmip6/.

Funding This research is supported by the Natural science foundation of Jiangsu Province (BK20200532), the National Natural Science Foundation of China (42005022, 41975116, 91937302, 41721004 and 42075033), the Fundamental Research Funds for the Central Universities (B210202139), and the Postdoctoral Science Foundation of Zhejiang Province (ZJ2020164). 
Conflicts of interest/Competing interests There are no conflicts of interest to declare.

Availability of data and material The data in this study are available for open access.

Code availability Not applicable

Authors' contributions All authors contributed to the concept and design of the research. WJ did the analysis and prepared the draft. HG, PH, LW, GH and LH acquired the funding and supervised the research. All authors contributed to the revising and editing of the paper.

Ethics approval Not applicable

Consent to participate Not applicable

Consent for publication All authors agree the submission and publication of the paper.

\section{References}

1. Bayr T, Latif M, Dommenget D, Wengel C, Harlass J, Park W (2018) Mean-state dependence of ENSO atmospheric feedbacks in climate models. Climate Dyn 50 (9-10):3171-3194.

2. Bayr T, Wengel C, Latif M, Dommenget D, Luebbecke J, Park W (2019) Error compensation of ENSO atmospheric feedbacks in climate models and its influence on simulated ENSO dynamics. Climate Dyn 53 (1-2):155-172.

3. Bellenger $\mathrm{H}$, Guilyardi E, Leloup J, Lengaigne M, Vialard J (2014) ENSO representation in climate models: from CMIP3 to CMIP5. Climate Dyn 42 (7-8):1999-2018.

4. Chang CP, Wang Z, H. H (2006) The Asian winter monsoon. The Asian Monsoon (Berlin: Springer Praxis Books):89-127.

5. Chen W, Graf HF, Huang RH (2000) The interannual variability of East Asian winter monsoon and its relation to the summer monsoon. Adv Atmos Sci 17 (1):48-60.

6. Chen W, Yang S, Huang RH (2005) Relationship between stationary planetary wave activity and the East Asian winter monsoon. J Geophys Res Atmos 110 (D14).

7. Chen Z, Wu R, Chen W (2014) Impacts of Autumn Arctic Sea Ice Concentration Changes on the East Asian Winter Monsoon Variability. J Climate 27 (14):5433-5450.

8. Cheung HHN, Zhou W (2015) Implications of Ural Blocking for East Asian Winter Climate in CMIP5 GCMs. Part I: Biases in the Historical Scenario. J Climate 28 (6):2203-2216.

9. Cheung HN, Zhou W, Mok HY, Wu MC (2012) Relationship between Ural-Siberian Blocking and the East Asian Winter Monsoon in Relation to the Arctic Oscillation and the El Nino-Southern Oscillation. J Climate 25 (12):4242-4257.

10. Chowdary JS, Parekh A, Gnanaseelan C, Sreenivas P (2014) Inter-decadal modulation of ENSO teleconnections to the Indian Ocean in a coupled model: Special emphasis on decay phase of El Niño. Global Planet Change 112:33-40. 
11. Collins M, An S-I, Cai W, Ganachaud A, Guilyardi E, Jin F-F, Jochum M, Lengaigne M, Power S, Timmermann A, Vecchi G, Wittenberg A (2010) The impact of global warming on the tropical Pacific ocean and El Niño. Nat Geosci 3 (6):391-397.

12. Ding Y (1994) Monsoons over China. Kluwer Academic:420 pp.

13. Eyring V, Bony S, MeehI GA, Senior CA, Stevens B, Stouffer RJ, Taylor KE (2016) Overview of the Coupled Model Intercomparison Project Phase 6 (CMIP6) experimental design and organization. Geoscientific Model Development 9 (5):1937-1958.

14. Feng J, Wang L, Chen W, Fong SK, Leong KC (2010) Different impacts of two types of Pacific Ocean warming on Southeast Asian rainfall during boreal winter. J Geophys Res Atmos 115.

15. Gill AE (1980) SOME SIMPLE SOLUTIONS FOR HEAT-INDUCED TROPICAL CIRCULATION. Quart J Roy Meteor Soc 106 (449):447-462.

16. Gong DY, Wang SW, Zhu JH (2001) East Asian winter monsoon and Arctic Oscillation. Geophys Res Lett 28 (10):2073-2076.

17. Gong H, Wang L, Chen W, Chen X, Nath D (2017) Biases of the wintertime Arctic Oscillation in CMIP5 models. Environmental Research Letters 12 (1).

18. Gong H, Wang L, Chen W, Nath D, Huang G, Tao W (2015) Diverse Influences of ENSO on the East Asian-Western Pacific Winter Climate Tied to Different ENSO Properties in CMIP5 Models. J Climate 28 (6):2187-2202.

19. Gong H, Wang L, Chen W, Wu R (2021) Evolution of the East Asian winter land temperature trends during 1961-2018: role of internal variability and external forcing. Environmental Research Letters 16 (2).

20. Gong H, Wang L, Chen W, Wu R, Wei K, Cui X (2014) The Climatology and Interannual Variability of the East Asian Winter Monsoon in CMIP5 Models. J Climate 27 (4):1659-1678.

21. Guilyardi E, Wittenberg A, Fedorov A, Collins M, Wang C, Capotondi A, van Oldenborgh GJ, Stockdale T (2009) Understanding El Niño in ocean-atmosphere general circulation models: progress and challenges. Bull Amer Meteor Soc 90 (3):325-+.

22. He C, Zhou T, Li T (2019) Weakened Anomalous Western North Pacific Anticyclone during an El NinoDecaying Summer under a Warmer Climate: Dominant Role of the Weakened Impact of the Tropical Indian Ocean on the Atmosphere. J Climate 32 (1):213-230.

23. Horel JD, Wallace JM (1981) Planetary-scale atmospheric phenomenon associated with the Southern Oscillation. Mon Wea Rev 109 (4):813-829.

24. Hu K, Huang G, Huang P, Kosaka Y, Xie S-P (2021) Intensification of El Nino-induced atmospheric anomalies under greenhouse warming. Nat Geosci.

25. Huang R, Chen J, Wang L, Lin Z (2012) Characteristics, processes, and causes of the spatio-temporal variabilities of the East Asian monsoon system. Adv Atmos Sci 29 (5):910-942.

26. Ji L, Sun S, Arpe K, Bengtsson L (1997) Model study on the interannual variability of Asian winter monsoon and its influence. Adv Atmos Sci 14 (1):1-1. 
27. Jiang DB, Hu D, Tian ZP, Lang XM (2020a) Differences between CMIP6 and CMIP5 Models in Simulating Climate over China and the East Asian Monsoon. Adv Atmos Sci 37 (10):1102-1118.

28. Jiang W, Huang G, Hu K, Wu R, Gong H, Chen X, Tao W (2017) Diverse relationship between ENSO and the Northwest Pacific summer climate among CMIP5 models: dependence on the ENSO decay pace. J Climate 30 (1):109-127.

29. Jiang W, Huang G, Huang P, Hu K (2018) Weakening of Northwest Pacific anticyclone anomalies during post-El Niño summers under global warming. J Climate 31 (9):3539-3555.

30. Jiang W, Huang P, Huang G, Ying J (2021) Origins of the Excessive Westward Extension of ENSO SST Simulated in CMIP5 and CMIP6 Models. J Climate 34 (8):2839-2851.

31. Jiang W, Huang P, Li G, Huang G (2020b) Emergent constraint on the frequency of central Pacific El Niño under global warming by the equatorial Pacific cold tongue bias in CMIP5/6 models. Geophys Res Lett 47 (19).

32. Kalnay E, Kanamitsu M, Kistler R, Collins W, Deaven D, Gandin L, Iredell M, Saha S, White G, Woollen J, Zhu Y, Chelliah M, Ebisuzaki W, Higgins W, Janowiak J, Mo KC, Ropelewski C, Wang J, Leetmaa A, Reynolds R, Jenne R, Joseph D (1996) The NCEP/NCAR 40-year reanalysis project. Bull Amer Meteor Soc 77 (3):437-471.

33. Kim ST, Yu J-Y (2012) The two types of ENSO in CMIP5 models. Geophys Res Lett 39.

34. Kug J-S, Ham Y-G, Lee J-Y, Jin F-F (2012) Improved simulation of two types of El Niño in CMIP5 models. Environmental Research Letters 7 (3).

35. Li G, Du Y, Xu H, Ren B (2015) An Intermodel Approach to Identify the Source of Excessive Equatorial Pacific Cold Tongue in CMIP5 Models and Uncertainty in Observational Datasets. J Climate 28 (19):7630-7640.

36. Li G, Jian Y, Yang S, Du Y, Wang Z, Li Z, Zhuang W, Jiang W, Huang G (2019) Effect of excessive equatorial Pacific cold tongue bias on the El Niño-Northwest Pacific summer monsoon relationship in CMIP5 multi-model ensemble. Climate Dyn 52 (9-10):6195-6212.

37. Li G, Xie S-P (2014) Tropical biases in CMIP5 multimodel ensemble: the excessive equatorial Pacific cold tongue and double ITCZ problems. J Climate 27 (4):1765-1780.

38. Ma T, Chen W, Feng J, Wu R (2018) Modulation effects of the East Asian winter monsoon on El Ninorelated rainfall anomalies in southeastern China. Scientific Reports 8.

39. Ma T, Chen W, Graf H-F, Ding S, Xu P, Song L, Lan X (2020) Different Impacts of the East Asian Winter Monsoon on the Surface Air Temperature in North America during ENSO and Neutral ENSO Years. $J$ Climate 33 (24):10671-10690.

40. Matsuno T (1966) Quasi-geostrophic motions in the equatorial area. J Meteor Soc Japan 44(1):2543.

41. Power SB, Delage F, Colman R, Moise A (2012) Consensus on twenty-first-century rainfall projections in climate models more widespread than previously thought. J Climate 25 (11):3792-3809. 
42. Smith TM, Reynolds RW, Peterson TC, Lawrimore J (2008) Improvements to NOAA's historical merged land-ocean surface temperature analysis (1880-2006). J Climate 21 (10):2283-2296.

43. Song X, Zhang GJ (2009) Convection parameterization, tropical Pacific double ITCZ, and upperocean biases in the NCAR CCSM3. Part I: climatology and atmospheric feedback. J Climate 22 (16):4299-4315.

44. Sun C, Yang S, Li W, Zhang R, Wu R (2016) Interannual variations of the dominant modes of East Asian winter monsoon and possible links to Arctic sea ice. Climate Dyn 47 (1-2):481-496.

45. Sun DZ, Fasullo J, Zhang T, Roubicek A (2003) On the radiative and dynamical feedbacks over the equatorial Pacific cold tongue. J Climate 16 (14):2425-2432.

46. Tao W, Huang G, Wu R, Hu K, Wang P, Gong H (2018) Origins of Biases in CMIP5 Models Simulating Northwest Pacific Summertime Atmospheric Circulation Anomalies during the Decaying Phase of ENSO. J Climate 31 (14):5707-5729.

47. Taylor KE, Stouffer RJ, Meehl GA (2012) AN OVERVIEW OF CMIP5 AND THE EXPERIMENT DESIGN. Bull Amer Meteor Soc 93 (4):485-498.

48. Wang B (1992) The vertical structure and development of the ENSO anomaly mode during 19791989. Journal of the Atmospheric Sciences 49 (8):698-712.

49. Wang B, Wu RG, Fu XH (2000) Pacific-East Asian teleconnection: how does ENSO affect East Asian climate? J Climate 13 (9):1517-1536.

50. Wang B, Wu Z, Li J, Liu J, Chang C-P, Ding Y, Wu G (2008a) How to measure the strength of the East Asian summer monsoon. J Climate 21 (17):4449-4463.

51. Wang B, Xiang BQ, Lee JY (2013) Subtropical High predictability establishes a promising way for monsoon and tropical storm predictions. Proc Natl Acad Sci U S A 110 (8):2718-2722.

52. Wang L, Chen W (2014) The East Asian winter monsoon: re-amplification in the mid-2000s. Chinese Science Bulletin 59 (4):430-436.

53. Wang L, Chen W, Huang R (2008b) Interdecadal modulation of PDO on the impact of ENSO on the east Asian winter monsoon. Geophys Res Lett 35 (20).

54. Wang L, Chen W, Zhou W, Chan JCL, Barriopedro D, Huang R (2010) Effect of the climate shift around mid 1970s on the relationship between wintertime Ural blocking circulation and East Asian climate. Int J Climatol 30 (1):153-158.

55. Wang L, Chen W, Zhou W, Huang R (2009a) Interannual Variations of East Asian Trough Axis at 500 hPa and its Association with the East Asian Winter Monsoon Pathway. J Climate 22 (3):600-614.

56. Wang L, Huang R, Gu L, Chen W, Kang L (2009b) Interdecadal Variations of the East Asian Winter Monsoon and Their Association with Quasi-Stationary Planetary Wave Activity. J Climate 22 (18):4860-4872.

57. Wang L, Lu M-M (2017) The East Asian Winter Monsoon. In: Chang CP, Kuo HC, Lau NC, Johnson RH, Wang B, Wheeler MC (eds). The Global Monsoon System: research and forecast, 3rd edn World Scientific, Singapore:51-61. 
58. Wu B, Su J, Zhang R (2011) Effects of autumn-winter Arctic sea ice on winter Siberian High. Chinese Science Bulletin 56 (30):3220-3228.

59. Wu BY, Wang J (2002) Winter Arctic Oscillation, Siberian High and East Asian winter monsoon. Geophys Res Lett 29 (19).

60. Xia Y, Hu Y, Liu J (2020) Comparison of trends in the Hadley circulation between CMIP6 and CMIP5. Science Bulletin 65 (19):1667-1674.

61. Xin XG, Wu TW, Zhang J, Yao JC, Fang YJ (2020) Comparison of CMIP6 and CMIP5 simulations of precipitation in China and the East Asian summer monsoon. Int J Climatol 40 (15):6423-6440.

62. Yang X, Huang P (2021) Restored relationship between ENSO and Indian summermonsoon rainfall around 1999/2000. The Innovation 2 (2).

63. Ying J, Huang P, Lian T, Tan H (2019) Understanding the effect of an excessive cold tongue bias on projecting the tropical Pacific SST warming pattern in CMIP5 models. Climate Dyn.

64. Zhang GJ, Song X (2010) Convection parameterization, tropical Pacific double ITCZ, and upperocean biases in the NCAR CCSM3. Part II: coupled feedback and the role of ocean heat transport. J Climate 23 (3):800-812.

65. Zhang RH, Sumi A, Kimoto M (1996) Impact of El Niño on the East Asian monsoon: A diagnostic study of the '86/87 and '91/92 events. J Meteor Soc Japan 74 (1):49-62.

66. Zhou S, Huang G, Huang P (2020) Inter-model Spread of the Changes in the East Asian Summer Monsoon System in CMIP5/6 Models. J Geophys Res Atmos 125 (24).

67. Zhou S, Huang P, Huang G, Hu K (2019) Leading source and constraint on the systematic spread of the changes in East Asian and western North Pacific summer monsoon. Environmental Research Letters 14 (12).

\section{Tables}

Table 1 The 20 CMIP5 and 20 CMIP6 models used in this study. 


\begin{tabular}{|lll|}
\hline & CMIP5 & CMIP6 \\
\hline 1 & ACCESS1-3 & BCC-CSM2-MR \\
\hline 2 & bCC-CSm1-1-m & CAMS-CSM1-0 \\
\hline 3 & BNU-ESM & CESM2-WACCM \\
\hline 5 & CanESM2 & CESM2 \\
\hline 6 & CCSM4 & CNRM-CM6-1 \\
\hline 7 & CESM1-CAM5 & CAnESM5 \\
\hline 8 & CMCC-CESM & EC-Earth3-Veg \\
\hline 9 & CSIRO-Mk3-6-0 & FGOALS-f3-L \\
\hline 10 & GFDL-ESM2G & FGOALS-g3 \\
\hline 11 & GFDL-ESM2M & GFDL-ESM4 \\
\hline 12 & GISS-E2-H & INM-CM4-8 \\
\hline 13 & GISS-E2-R & IPSL-CM6A-LR \\
\hline 14 & IPSL-CM5A-LR & KACE-1-0-G \\
\hline 15 & IPSL-CM5A-MR & MIROC-ES2L \\
\hline 16 & MIROC-ESM & MIROC6 \\
\hline 17 & MIROC-ESM-CHEM & MPI-ESM1-2-HR \\
\hline 18 & MPI-ESM-LR & MRI-ESM2-0 \\
\hline 19 & MPI-ESM-MR & NESM3 \\
\hline 20 & MRI-CGCM3 & UKESM1-0-LL \\
\hline & & \\
\hline
\end{tabular}

Figures 
(a) OBS

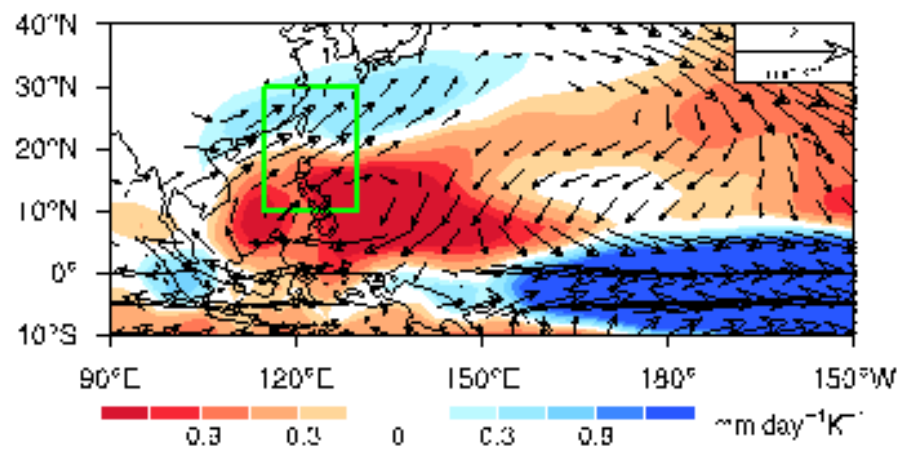

(b) MME of CMIP5

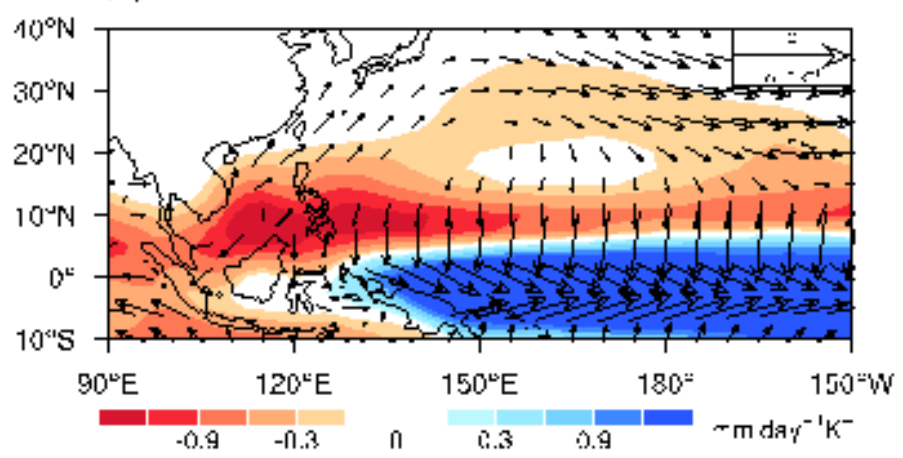

(c) MME of CMIPG

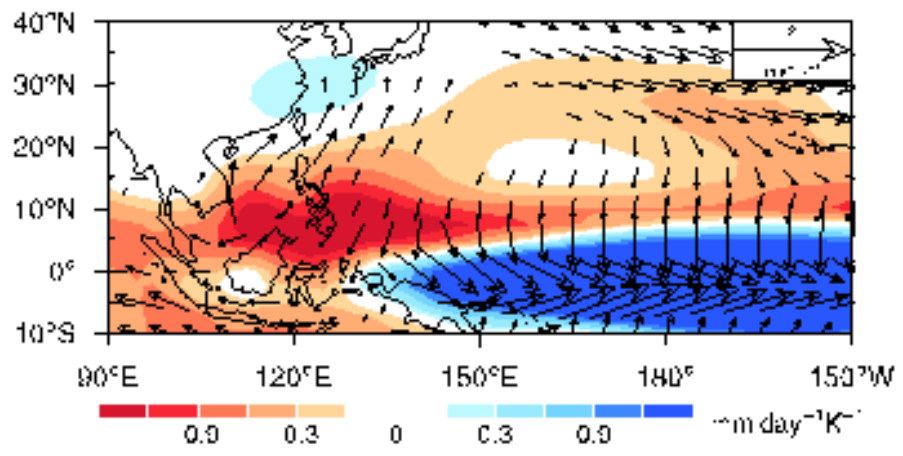

(d) bias in CMIP5

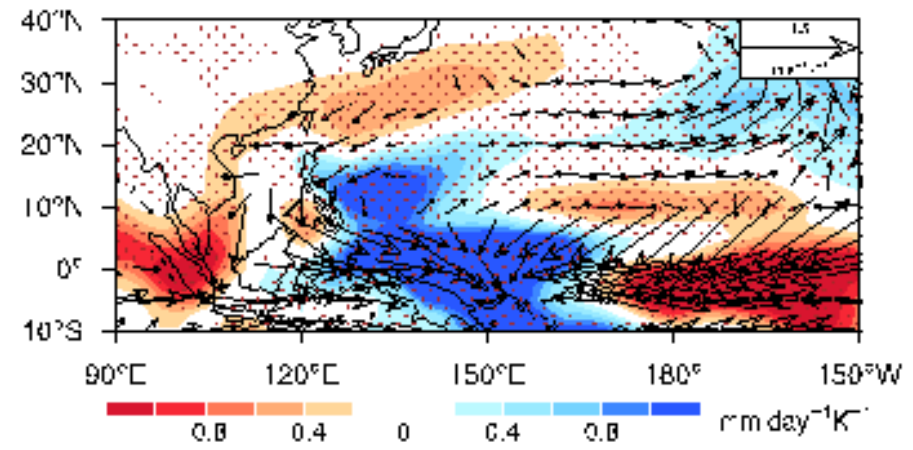

(e) bias in CMIP6

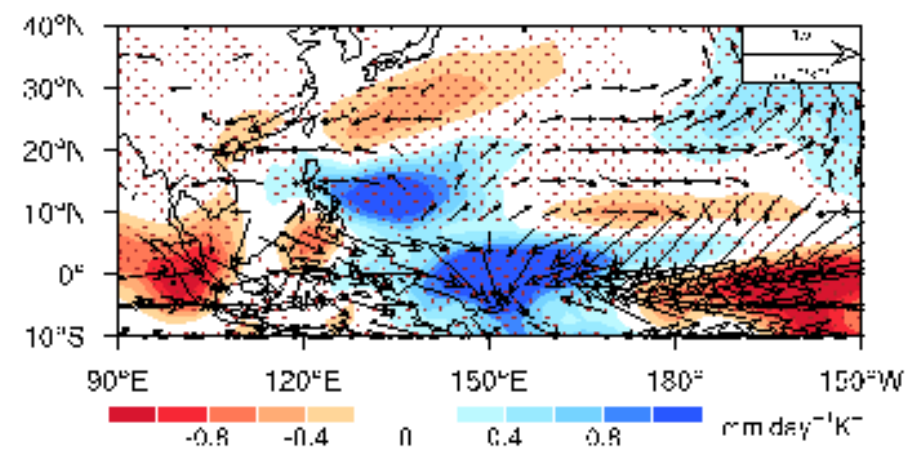

(f) $\mathrm{c}-\mathrm{b}$

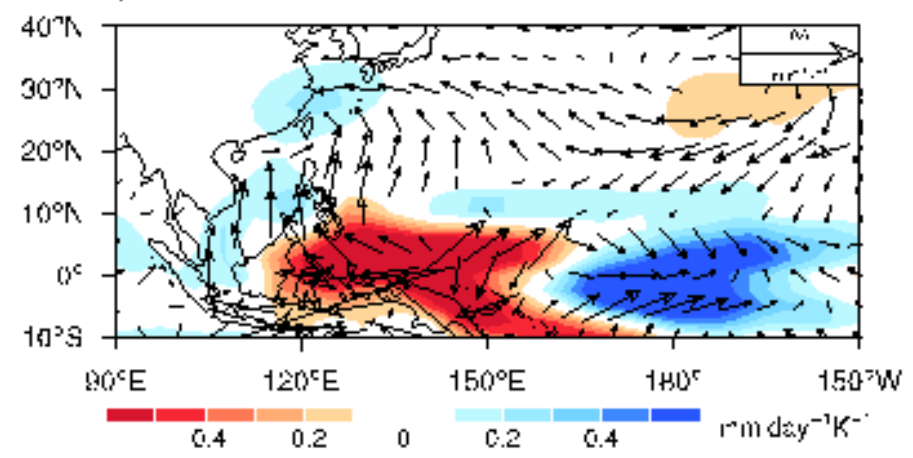

\section{Figure 1}

Precipitation anomalies and 850-hPa wind anomalies regressed onto the unstandardized Niño-3.4 index during the ENSO mature winter in (a) observations, (b) the MME of 20 CMIP5 models and (c) the MME of 20 CMIP6 models. Correspondingly, their biases in (d) CMIP5, (e) CMIP6 and (f) the differences between the two generation models. The regions where the sign of the MME agreed by more than $70 \%$ of models are stippled. 


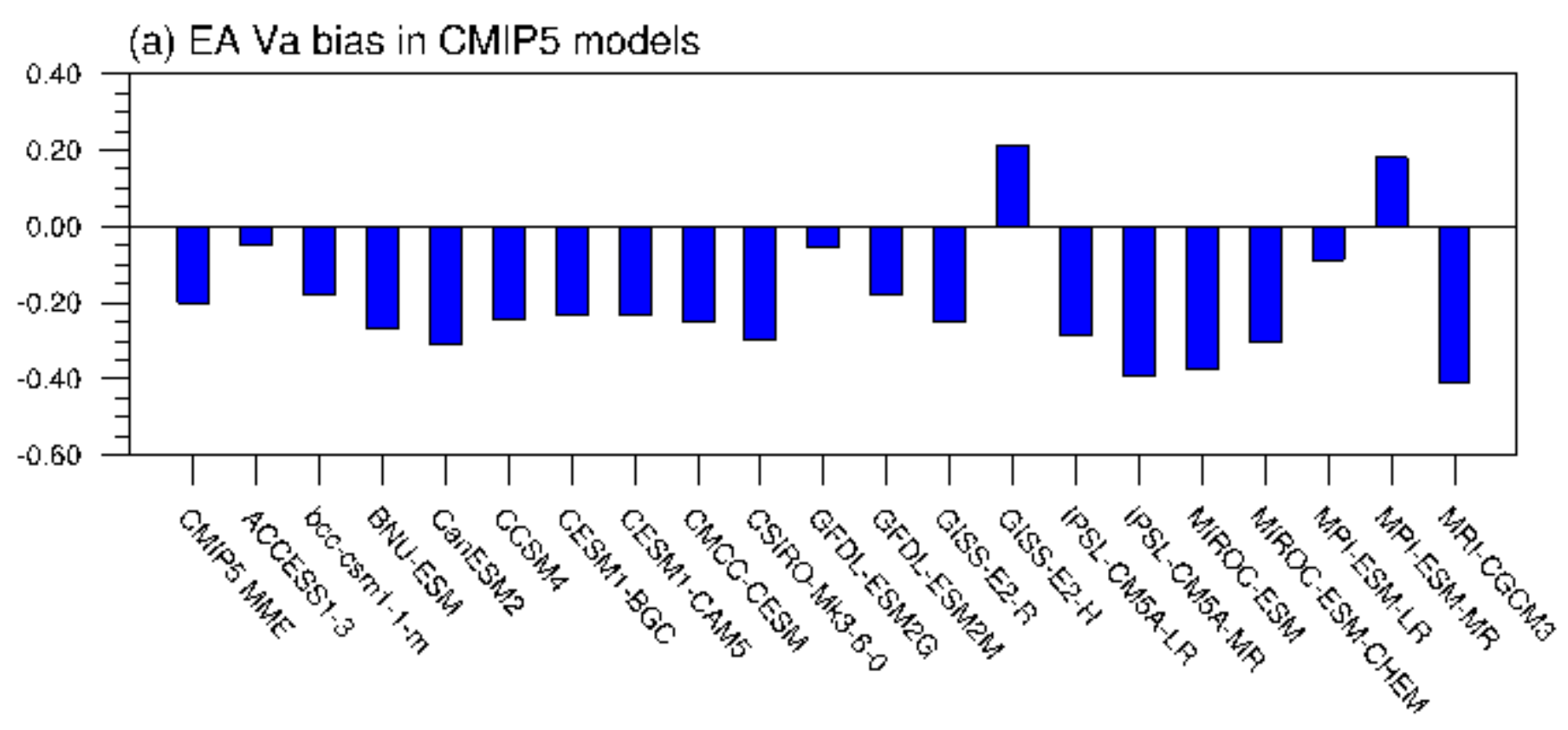

(b) EA Va bias in CMIP6 models

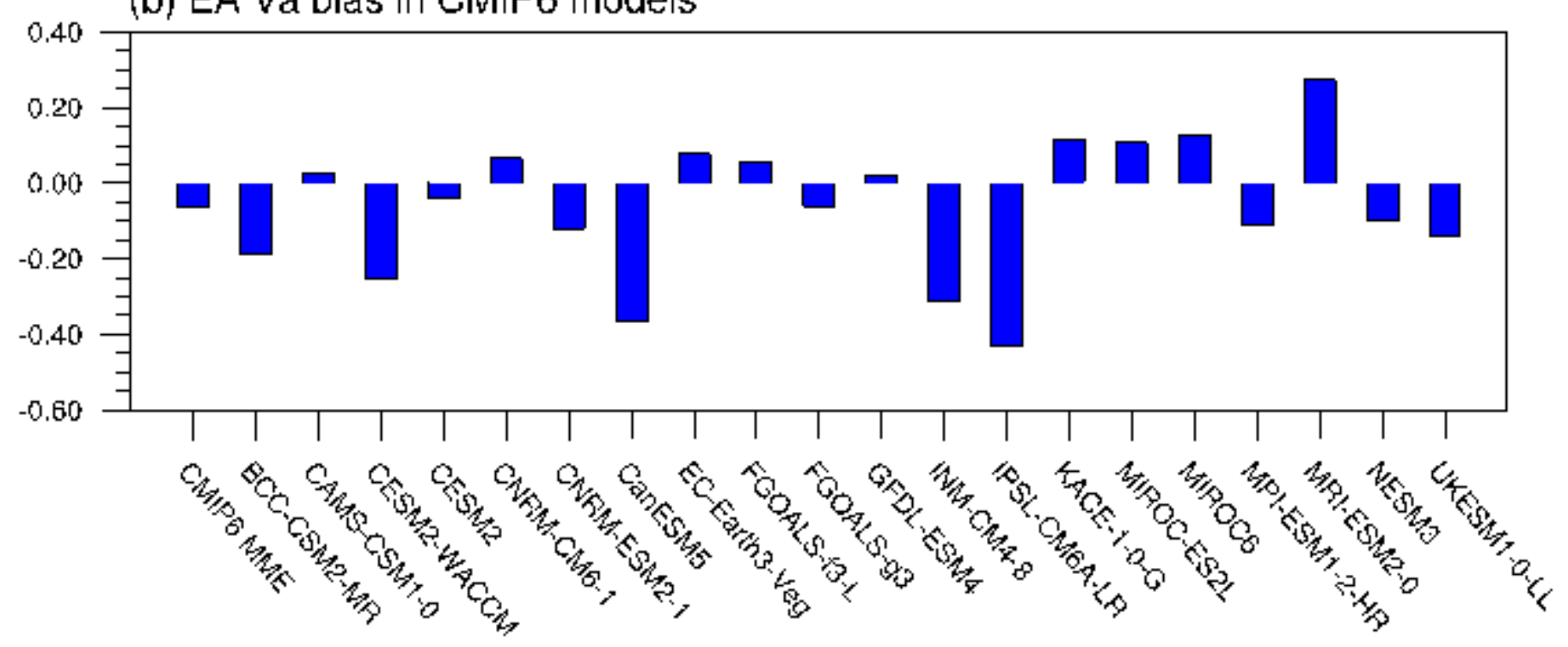

Figure 2

ENSO-related $1000-\mathrm{hPa}$ meridional wind anomaly bias in the East Asia $\left(10^{\circ}-30^{\circ} \mathrm{N}, 115^{\circ}-130^{\circ} \mathrm{E}\right)$ (the region is selected as the EAWM index defined by Ji et al. 1997 and highlighted by a green box in Fig. 1a) in (a) CMIP5 models and in (b) CMIP6 models. 
(a) EOF1

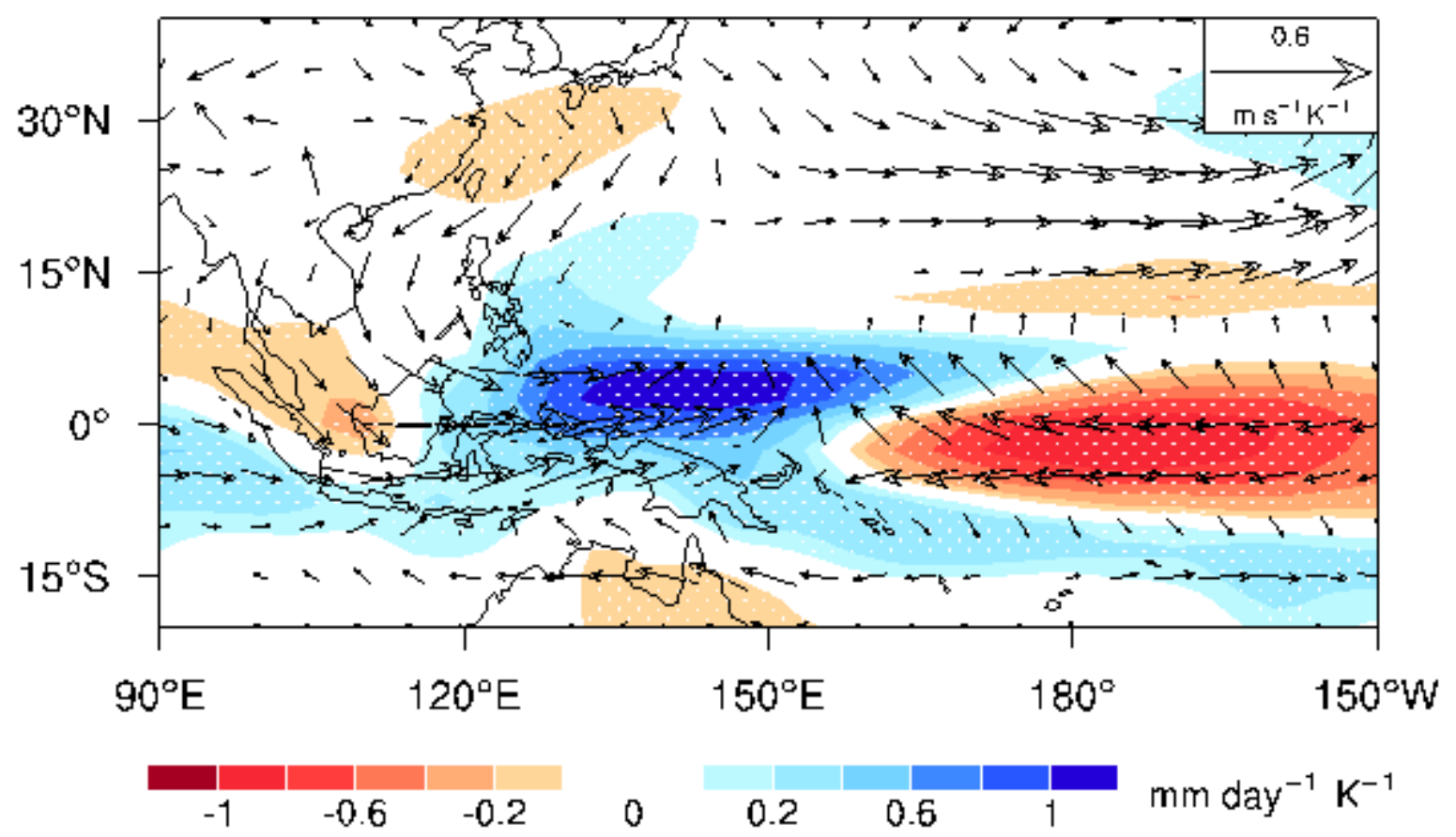

(b) PC1

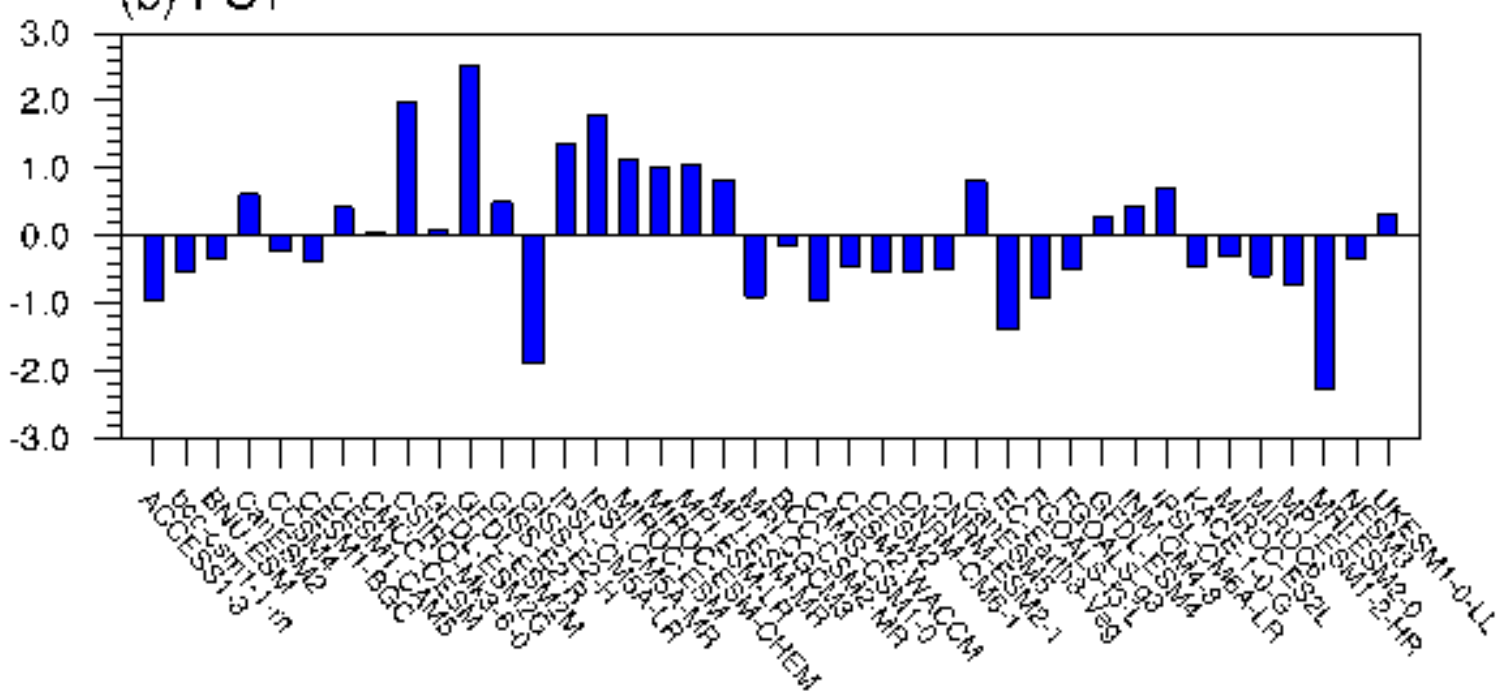

Figure 3

(a) The leading mode (EOF1) derived from inter-model MV-EOF analysis on the simulated ENSO-related rainfall (shading) and 850-hPa wind anomalies (vectors). (b) Normalized first PC of the MV-EOF analysis. 
(a) SST anomalies

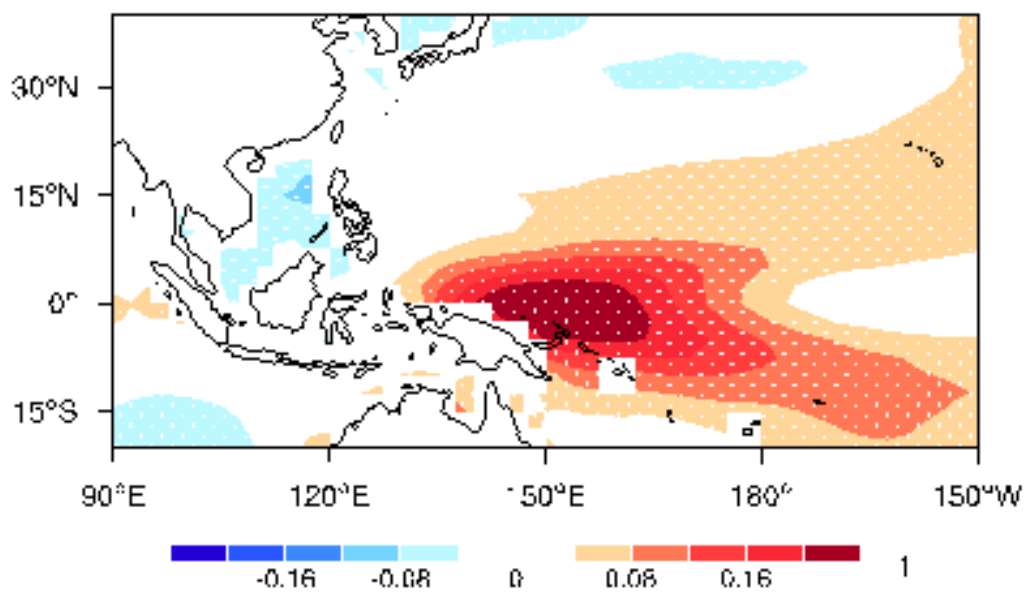

(b) Tropospheric temperature anomalies

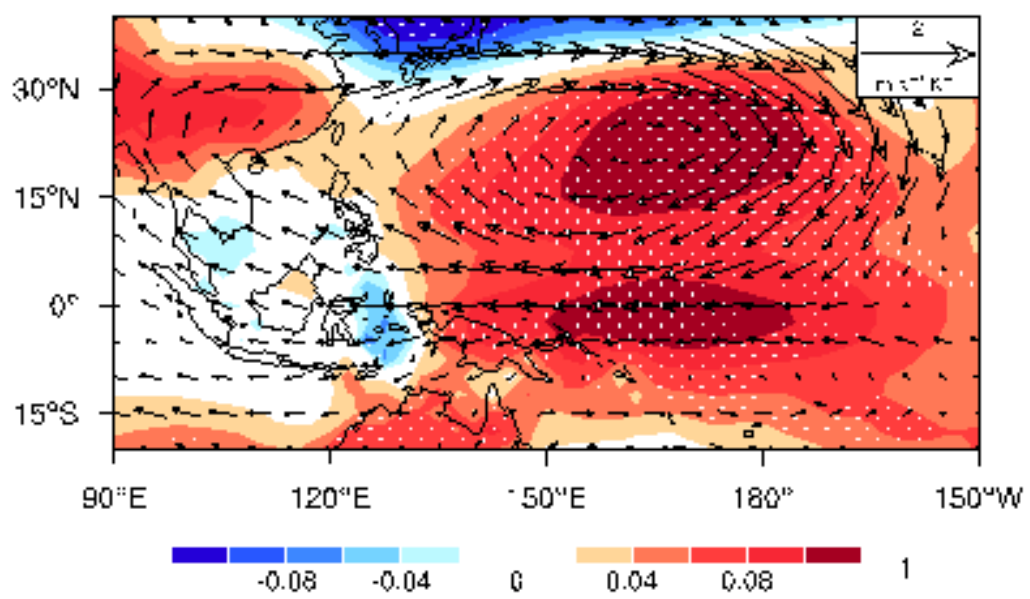

(c) Streamfuction\& rotation wind anomalies

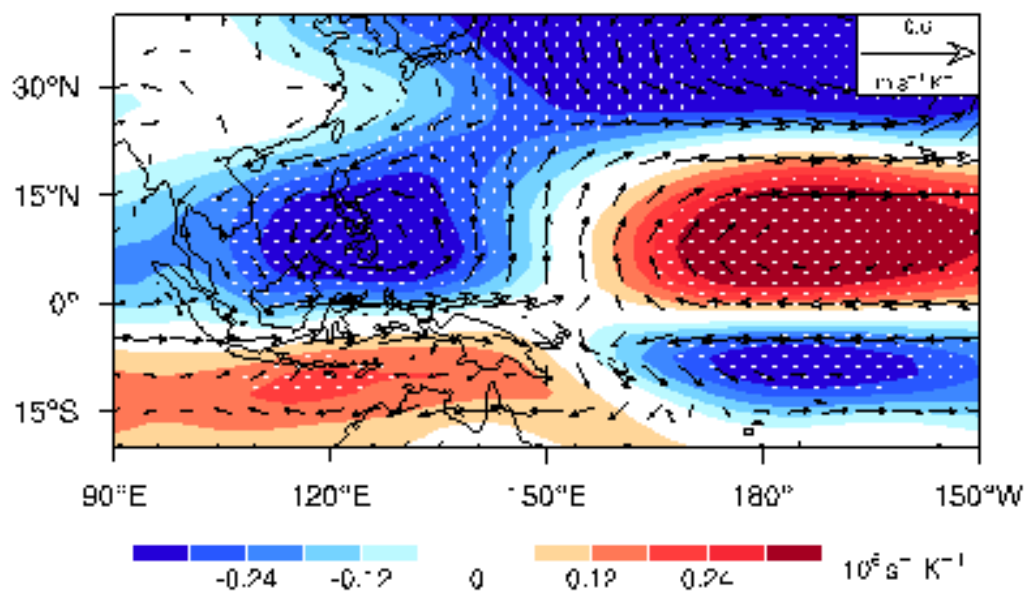

Figure 4

Inter-model regressions of the (a) ENSO-related SST anomalies, (b) 1000-200-hPa mean tropospheric temperature anomalies (shading) and 200-hPa rotational winds anomalies and (c) 850-hPa streamfunction (shading) and rotational winds anomalies (vectors) onto the normalized PC of the first MV-EOF mode. Stippling indicates the regressions are significant at the $95 \%$ confidence level, based on the Student's t test. 
(a) Wind\&rainfall anomalies

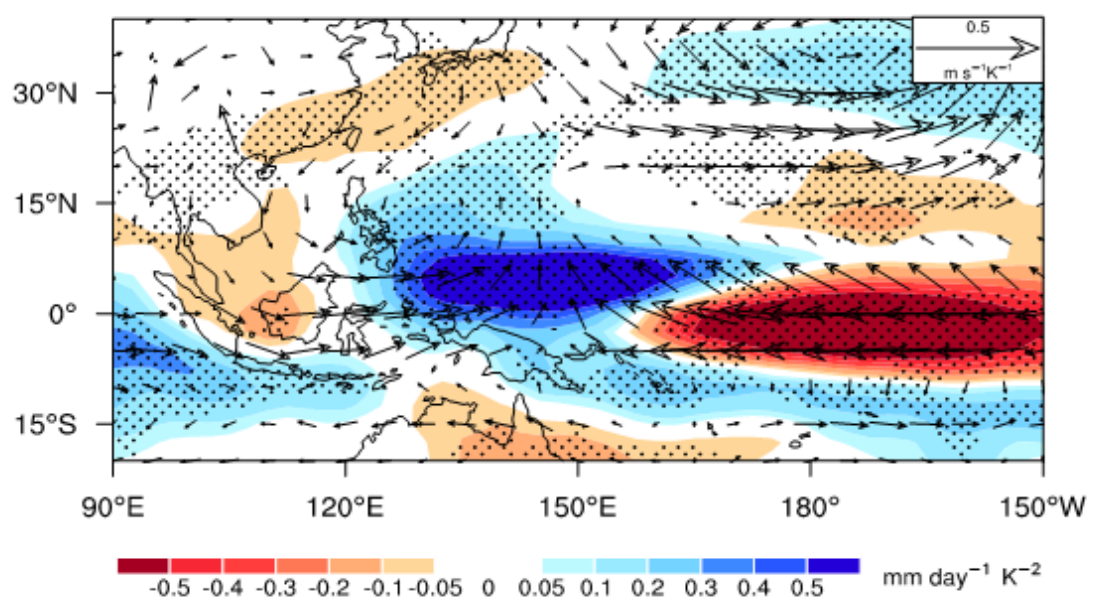

(b) SST anomalies
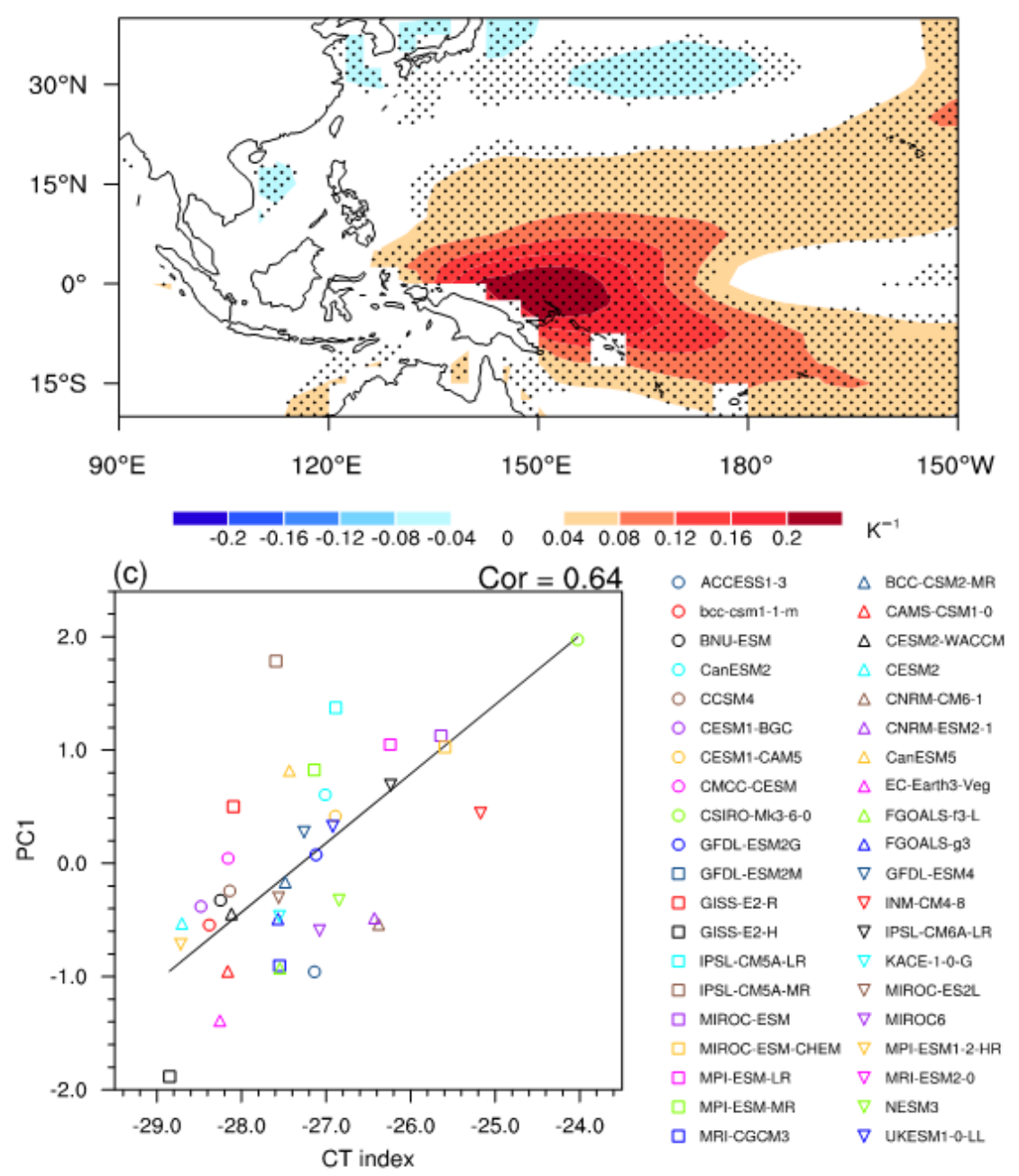

\section{Figure 5}

Intermodel regression of (a) ENSO-related rainfall (shading), 850-hPa wind (vectors), and (b) SST (shading) anomaly bias onto CT index. (c) Relationship between PC1 and CT index in the 40 models. The intermodel correlation coefficient is shown in the top-right of the panel and is significant at the $95 \%$ confidence level, based on the Student's t-test. Stippling in (a) and (b) indicates the regressions are significant at the $95 \%$ confidence level, based on the Student's t test. 

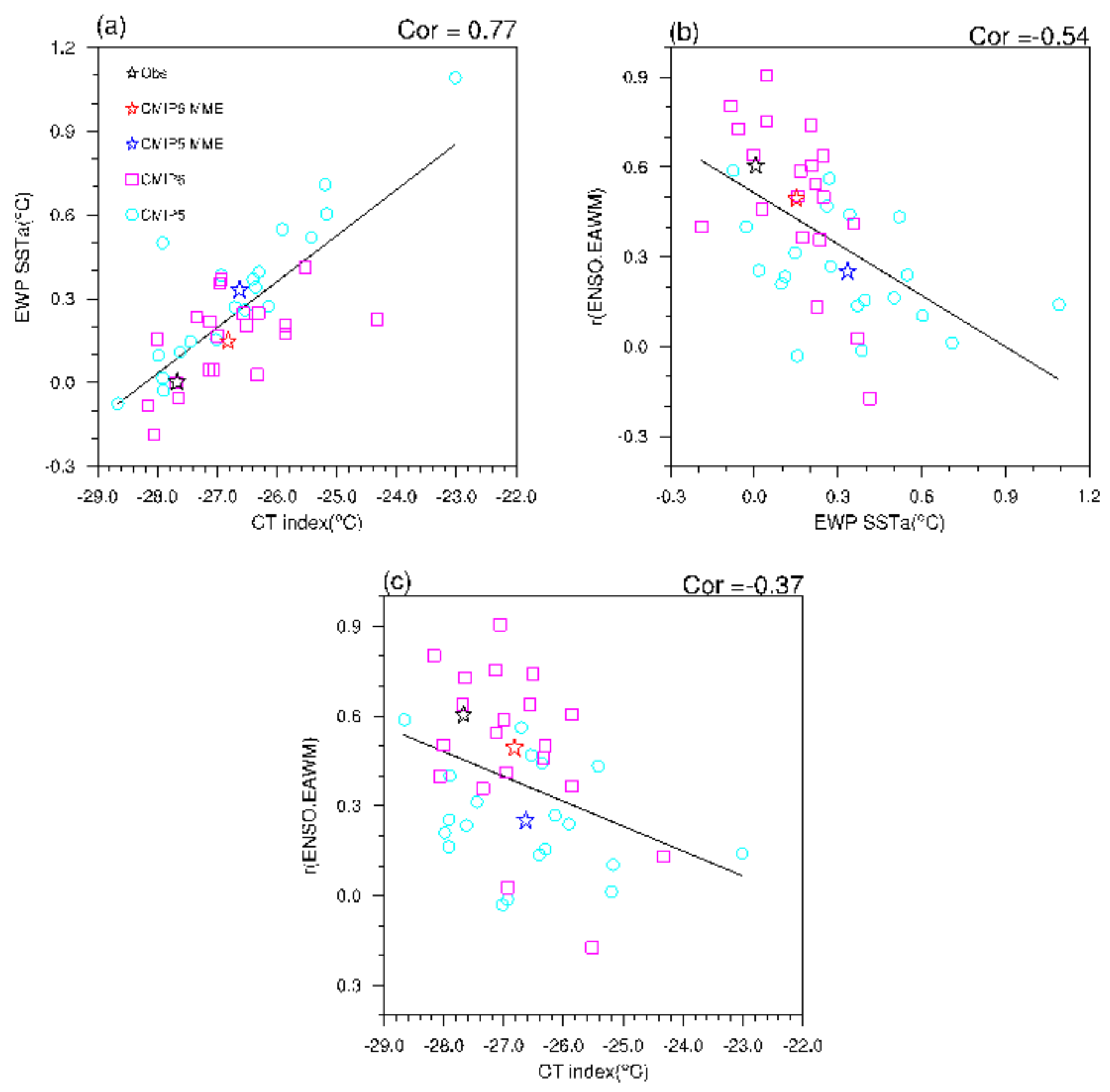

\section{Figure 6}

Scatterplots of the simulated EWP SST anomaly $\left(5^{\circ} \mathrm{S}-5^{\circ} \mathrm{N}, 140^{\circ}-180^{\circ}\right)$ versus (a) the CT index and (b) the relationship between ENSO and EAWM [index defined as 1000-hPa meridional wind anomaly $\left(10^{\circ}-\right.$ $30^{\circ} \mathrm{N}, 115^{\circ}-130^{\circ} \mathrm{E}$ )] in 40 models. (c) Scatterplots of the CT index versus the relationship between ENSO and EAWM in 40 models. Black lines denote the linear fit of 40 models. The intermodel correlation coefficients of the 40 models are shown in the top-right of the panels. All correlation coefficients are significant at the $95 \%$ confidence level, based on the Student's $t$ test. 
(a) ENSO SST in OBS

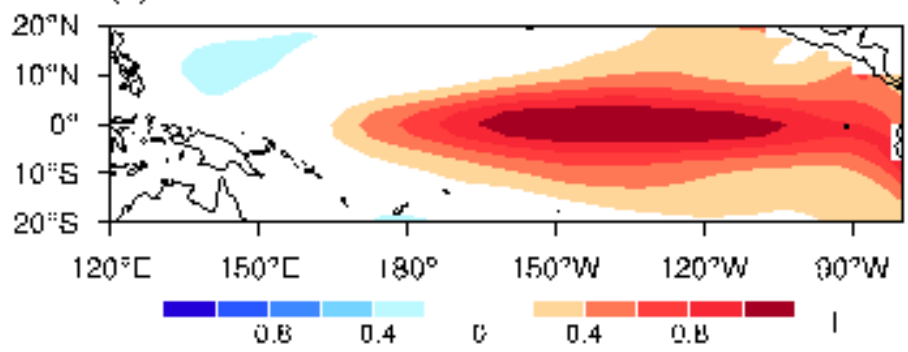

(b) ENSO SST in CMIP5

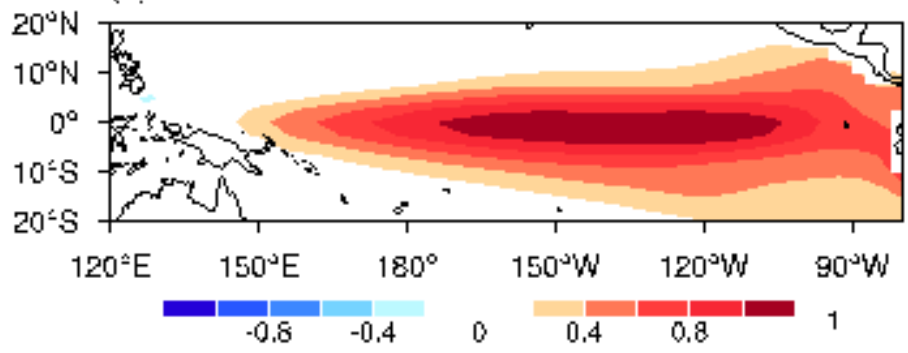

(c) ENSO SST in CMIP6

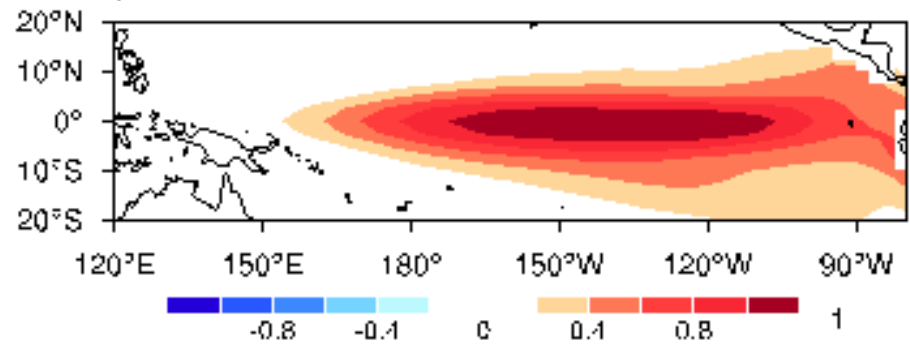

(d) ENSO SST bias in CMIP5

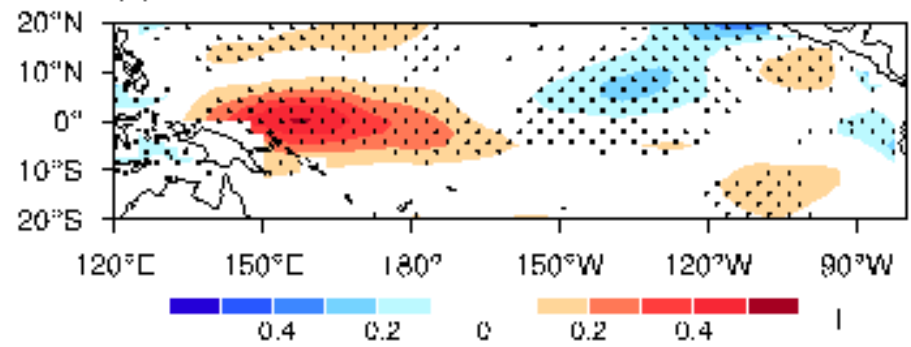

(e) ENSO SST bias in CMIP6

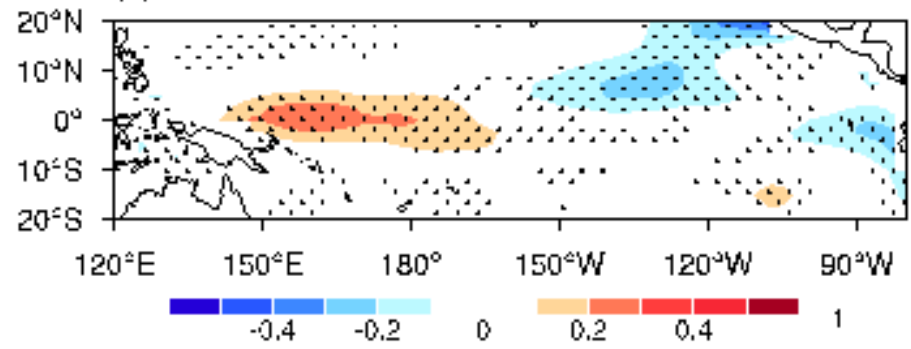

(I) $a-b$

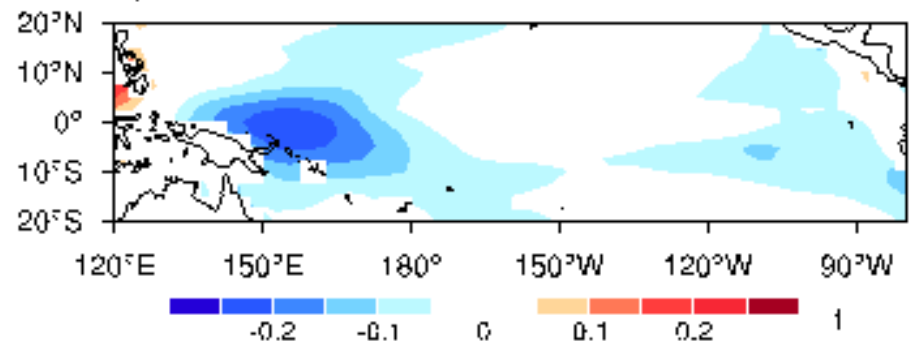

Figure 7

As in Fig. 1, but for ENSO SST anomaly 
(a) Clim SST in OBS

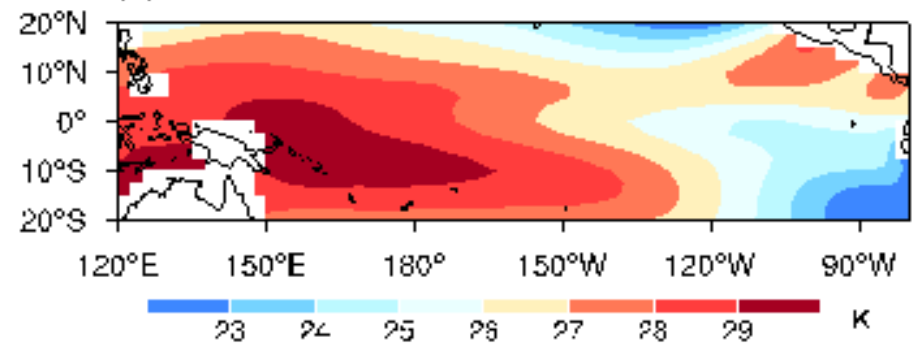

(b) Clim SST in CMIP5

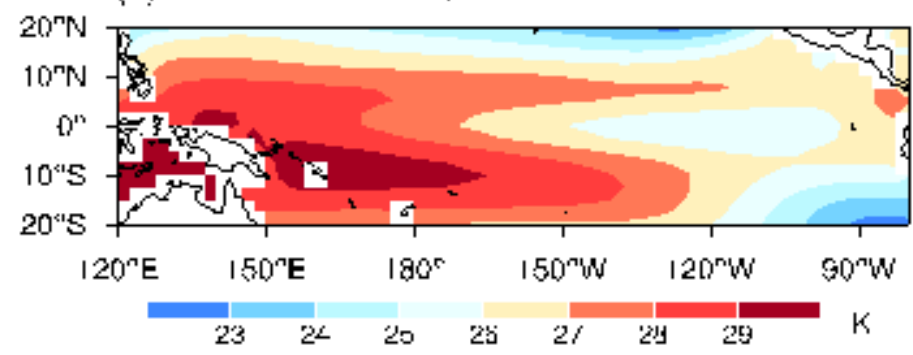

(c) Clim SST in CMIPG

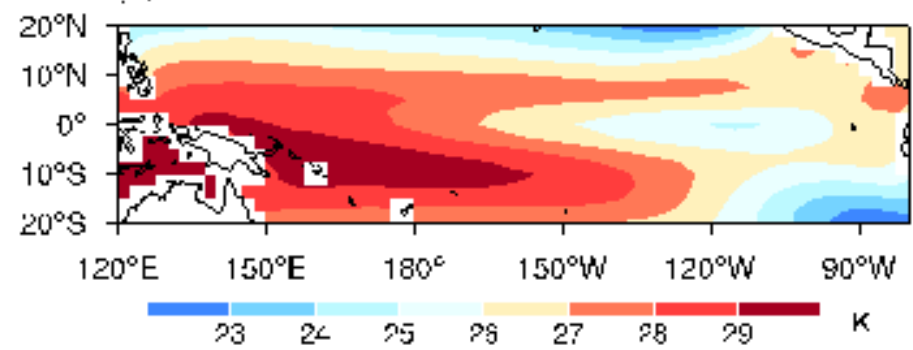

Figure 8

As in Fig. 1, but for SST mean state. (d) SST bias in GMIP5

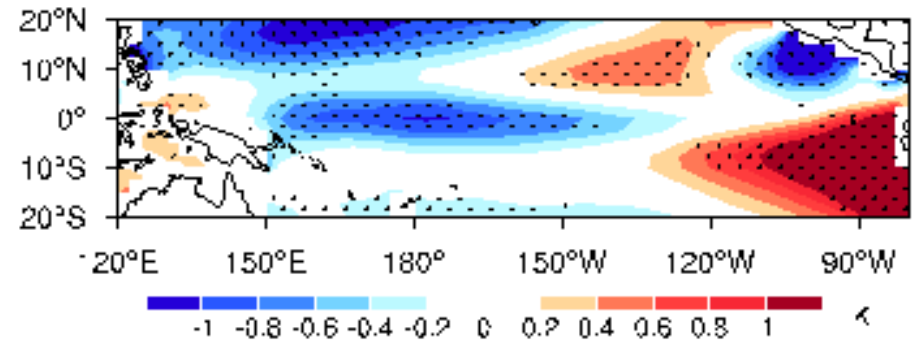

(e) SST bias in CMIPG

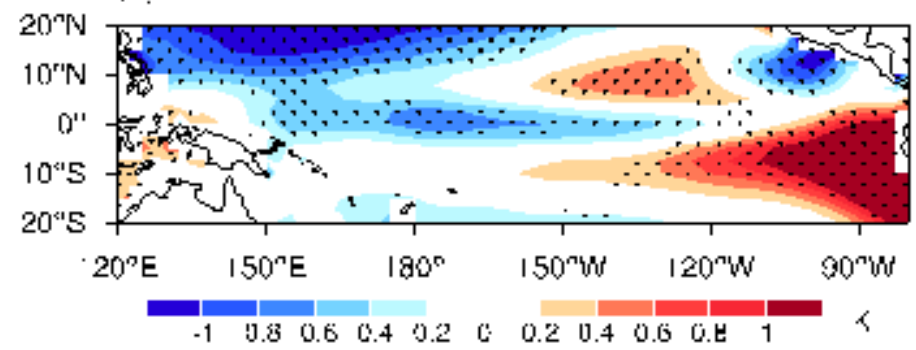

(f̣) $c-b$

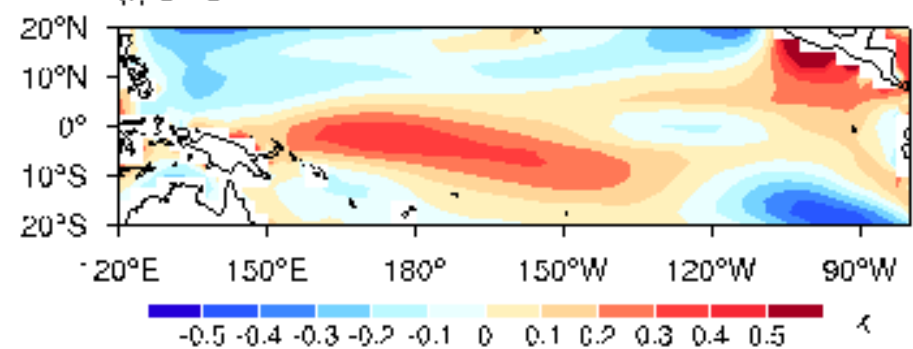

